\section{VISIÓN PANORAMICA DE LA PRUEBA EN EL RECONOCIMIENTO DE DERECHOS SUSTANCIALES DEL TRABAJADOR*}

\author{
A PANORAMIC VIEW OF PROOF IN THE \\ RECONGNITION OF SUBSTANTIAL RIGHTS \\ OF WORKERS
}

\author{
VISÃO GERAL DA PROVA NO RECONHECI- \\ MENTO DOS DIREITOS SUBSTANCIAIS DO \\ TRABALHADOR
}

\section{RESUMEN}

En materia laboral se plantea la necesidad de analizar la pertinencia de adoptar distintas medidas sustanciales y/o procesales que conlleven a una mayor eficiencia y eficacia en el reconocimiento de los derechos de los trabajadores por parte de las autoridades administrativas y judiciales que garanticen la protección real de la parte débil de la relación laboral, la cual históricamente ha tenido un papel relevante en los cambios sociales, políticos y económicos de los Estados, lo que implica revisar y aplicar en conjunto todas las normas y principios que propenden por el respeto de sus derechos a través de figuras como la interpretación flexible del derecho, la creatividad en la construcción de precedentes administrativos judiciales y "la carga dinámica de la prueba" en procura de que las pretensiones justas de los trabajadores no sean revisadas bajo

\footnotetext{
* Artículo de investigación resultado del proyecto de investigación "El papel de la prueba para el trabajador en los procesos laborales y trámites administrativos para el reconocimiento de prestaciones sociales y económicas". Línea de investigación: Derecho Laboral y Seguridad Social". Centro de Investigación: Francisco de Vittoria. Universidad Santo Tomas de Aquino.

a. Abogada egresada de la Universidad Libre de Colombia, Especialista en Relaciones Laborales de la UNAB, Especialista y Magister en Derecho Laboral de la Universidad Nacional de Colombia, Docente de la Universidad Santo Tomas y otras universidades
}

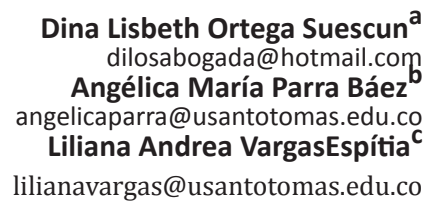

lilianavargas@usantotomas.edu.co

Fecha de recepción: 27 de Octubre 2014 Fecha de revisión: 22 de Diciembre 2014 Fecha de aceptación: 09 de Febrero 2015

\footnotetext{
MISIÓN JURÍDICA Revista de Derecho y Ciencias Sociales Bogotá, D.C. (Colombia) Colaboradores Externos Internacionales Núm. 8, Año 2015 enero-junio, pp. 113-131. ISSN 1794-600X
} 
excesivos formalismos o bajo deficiencias de valoración probatoria.

En el presente artículo, el lector encontrara una descripción panorámica de la normatividad y del manejo de la prueba en materia laboral en Colombia, normas analizadas desde una perspectiva hermenéutica, es decir, considerando los elementos de validez, legitimidad y eficacia, y pruebas revisadas a nivel práctico; por cuanto las Organizaciones Internacionales, son agentes activos en la elaboración de normatividad, que acepten los países miembros, para mejorar las situaciones laborales y de calidad de vida, de los habitantes del mundo, pese a ello encontramos que aún con la aprobación de los acuerdos y tratados internacionales por Colombia, las barreras procesales y probatorias, pueden ser más poderosas, generando en el trabajador una renuncia a sus reclamaciones.

Desarrollamos en tal sentido, la teoría de la independencia del derecho laboral de las demás áreas del derecho, considerando incluir, la separación del derecho laboral y de la seguridad social, en virtud de las diversas formas de contratación laboral y civil, que proliferan en los ambientes comerciales, abriendo una brecha, entre los derechos laborales y los derechos sociales, considerando importante la función jurisdiccional, para la solución de los conflictos que desde la competencia, son un apuro para las partes. Este artículo, es el inicio del largo y atropellado camino, con miras a encontrar el equilibrio entre los derechos y las formas procesales de reclamarlos, en un conflicto laboral.

\section{PALABRAS CLAVE}

Carga procesal, carga de la prueba, carga dinámica de la prueba, derechos sustanciales, trabajador, funcionario administrativo, juez, proceso.

del país. Directora del Grupo de Investigación en el Derecho del Trabajo y la Seguridad Social en la Universidad Santo Tomás Sede Bogotá.

b. Abogada de Universidad Santo Tomas de Aquino. Especialista en Derecho de la empresa y derecho comercial de la Universidad del Rosario. Magister en Historia de la Universidad Pedagógica y Tecnológica de Colombia. Docente Régimen Pensional Colombiano de la Universidad Santo Tomas de Aquino. c. Abogada de Universidad Santo Tomas de Aquino. Especialista en Derecho Laboral de la Pontificia Universidad Javeriana. Profesora de Derecho Laboral Individual, Derecho Colectivo y Técnicas de Negociación Colectiva de la Universidad Santo Tomas de Aquino.

\section{ABSTRACT}

Regarding labor it is considered the necessity to analize the pertinence of adopting different substantive and procedural measures that bring a greater efficiency and effectiveness in the recognition of the rights of workers by administrative and judicial authorities that guarantee the real protection of the weak part in the labor relations, which historically has had a relevant role in social, political and economic changes of the States. This implies checking and applying as a whole all norms and principles that lead to the respect of its rights through figures such as the flexible interpretation of rights, the creativity in the construction of administrative judicial precedents and the "dynamic burden of proof" in procurement that the just pretention of workers would not be examined under excessive formalisms or under deficiency of evidentiary valuation.

In this article the reader will find a panoramic description of rules and handling of the proof in labor matter in Colombia, norms that are analyzed from an hermeneutic view, that is considering the validity, legitimacy and effectiveness elements and proof in a pragmatic level. This is why International Organizations are active agents in the elaboration of rules that the member countries support to improve the situation of workers and quality of life inhabitants have worldwide. In spite of this we still find that, in Colombia, even with the approval of the international agreements and treaties the procedural barriers and in the evidentiary stage can be more powerful, generating in the worker a renounce to his complaints.

In this direction we have developed the theory of independence on labor law from the other areas in law, considering to include the separation between labor law and social security, in virtue of the different types of contracting, labor and civil, that proliferate in commercial environments, opening a breach among the labor and social rights, considering important the jurisdictional function for the solution of conflicts that are difficult situations for the parties. This study is the beginning of a long and winding road, with the goal to find balance between types of laws and the procedural ways to claim them in a labor conflict. 


\section{KEYWORDS}

Procedural burden, burden of proof, dynamic burden of proof, substantive law, worker, administrative officer, judge, trial.

\section{RESUMO}

No plano laboral surge a necessidade de se analisar a adequação de diferentes medidas de sustentação e / ou procedimentais que conduzam a uma maior eficiência e eficácia no reconhecimento dos direitos dos trabalhadores por parte das autoridades administrativas e judiciais, para assegurar uma proteção eficaz da parte mais fraca na relação de trabalho, que tem historicamente desempenhado um papel importante nas mudanças sociais, políticas e econômicas dos Estados. Isso implica em revisar e aplicar, em conjunto, todas as normas e princípios que promovam o respeito pelos seus direitos, através de figuras como a interpretação flexível da lei, a criatividade na construção de precedentes administrativos - judiciais e "carga dinâmica da prova" -, a fim de que as justas reivindicações dos trabalhadores não sejam revisadas por excesso de formalismo ou por deficiências de valoração da prova.

Neste artigo, o leitor encontrará uma visão geral das normas e do gerenciamento das provas em questões trabalhistas na Colômbia, padrões analisados a partir de uma perspectiva hermenêutica, ou seja, considerando-se os elementos de validade, legitimidade e eficácia, e dados analisados a nível prático, porque as organizações internacionais são agentes ativos do desenvolvimento de regulamentos, que aceitam os países membros para melhorar as condições de emprego e a qualidade de vida dos povos do mundo. No entanto, descobriu-se que, mesmo com a aprovação de acordos e os tratados internacionais na Colômbia, as barreiras processuais e probatórias podem ser mais poderosas, resultando na renúncia do trabalhador às suas reivindicações.

Desenvolvemos neste sentido, a teoria da independência do Direito do Trabalho de outras áreas do Direito, considerando inclusive a separação do Direito do Trabalho da segurança social, em razão das várias formas de contratos trabalhistas e cíveis, que proliferam em ambientes comerciais, abrindo uma brecha entre os direitos trabalhistas e os direitos sociais, destacando como importante a função judicial para resolver os conflitos de competência, os quais representam um problema para as partes. Este artigo é o início de um longo caminho, com vista a encontrar o equilíbrio entre os direitos e as formas processuais de reclamá-los em uma disputa trabalhista.

\section{PALAVRAS-CHAVE}

Carga processual, ônus da prova, carga dinâmica da prova, direitos substanciais, trabalhador, agente administrativo, juiz, processo.

\section{INTRODUCCIÓN}

Considerando el desarrollo que en materia de garantía de los derechos laborales ha tenido la legislación colombiana, tal y como lo demuestra el artículo 25 de la Constitución Política, que a su tenor contempla: "El trabajo es un derecho y una obligación social y goza, en todas sus modalidades, de la especial protección del Estado. Toda persona tiene derecho a un trabajo en condiciones dignas y justas.", y el artículo 48, de la misma Carta, que concibe a la Seguridad Social como un derecho del orden fundamental, así como posteriormente en la ley 100 de 1993, es necesario establecer si en los procesos judiciales y/o administrativos prima el derecho sustancial sobre el procesal o, por el contrario, se dejan de reconocer los derechos de los trabajadores como consecuencia de exigencias $\mathrm{y}$ formalismos excesivos.

Dentro de la legislación procesal laboral encontramos obligaciones probatorias asignadas al trabajador, respecto de las cuales cabe preguntarse, atendiendo a la realidad laboral de los trabajadores en Colombia, si existe una carga excesiva, que conlleva finalmente al desconocimiento del derecho sustancial y a la renuncia tácita para acudir a la justicia, ante la imposibilidad de éste trabajador de reunir el material probatorio impuesto y necesario para reclamar un derecho laboral y/o de la seguridad social; o si, por el contrario, la legislación procesal laboral ofrece las garantías y el equilibrio probatorio a las partes de la relación laboral, empleador y trabajador, a fin de conservar la armonía y justicia social en ejecución de la relación laboral.

En principio estimamos necesario, establecer la evolución que existe en cuanto al derecho al trabajo y el derecho a la seguridad social y que 
se materializa a través de normas positivas tales como: la Constitución Política de Colombia, el Código Sustantivo de Trabajo, Código Procesal del Trabajo y Seguridad Social y demás normas complementarias, así como de las que siendo parte del Derecho civil, han permeado las relaciones laborales a través de desarrollos contractuales comerciales.

La revisión panorámica de la protección laboral de la parte denominada "trabajador" en Colombia, nos permitirá establecer las posibles falencias de la legislación en su estructura normativa y/o en su aplicación y así lograr determinar si, a pesar de existir multiplicidad de normas proteccionistas, las mismas no logran ser lo suficientemente eficientes al momento de reconocer los derechos sustanciales de los trabajadores.

En este orden, encontramos la comprensión hermenéutica del derecho (Viola y Zaccaria, G., 1999), con una visión según Mejía (2005) que articule la legitimidad, la validez y la eficacia de las normas, para resaltar el carácter interpretativo de las mismas, y principios relativos al derecho al trabajo y a la seguridad social, considerando la vinculación de los textos jurídicos con los contextos problemáticos, para formular soluciones confiables al problema socio - jurídico - procesal que se plantea.

$\mathrm{Si}$ esperamos avanzar en términos de eficacia en las relaciones laborales, mejorar las condiciones de vida de los trabajadores y permitir el desarrollo de las actividades económicas para los empresarios, debemos incluir el componente de legitimidad y aplicabilidad de las normas que rigen el Derecho Laboral y de la Seguridad Social, vinculando el estudio interdisciplinario, reconociendo la presencia de problemas reales respecto de los modelos teóricos y no, como se hace hasta el momento, sin resultados positivos, acomodar la realidad a los modelos teóricos impuestos, los cuales no dan respuestas aceptadas a los problemas sociales existentes.

Por lo tanto, resulta oportuno contextualizar y formular primigenios diagnósticos para un mundo cada vez más globalizado y una época que, como lo dijo Franceso Galgano: "es siempre más mutante en el tiempo y uniforme en el espacio" (Galgano, 2005 , p.127), es decir con profundos y rápidos cambios en los actores sociales, su interacción, sus problemáticas y sus soluciones. Es así como al realizar una revisión doctrinaria, jurisprudencial y legal del hoy denominado Derecho Laboral y de la Seguridad Social, se plantean ciertos cuestionamientos acerca de la legitimidad, validez y funcionalidad normativa así como de la estructura administrativa y judicial que permita el acceso de los trabajadores a la administración en Colombia y a los estrados judiciales en procura de la protección de sus derechos sustanciales.

Tanto la economía y la sociedad han confrontado cambios importantes derivados de la globalización de los procesos productivos, los que nacen como consecuencia de los cambios demográficos (envejecimiento de la población, disminución de las tasas de natalidad); sociales (predominio de la familia nuclear sobre la extensa); familias monoparentales; incorporación masiva de las mujeres al mundo laboral; y en mayor proporción dentro de la amplitud del problema, los procesos masivos de inmigración no controlados, por la violencia o el desplazamiento en busca de un mejor ingreso en la ciudad, trayendo consigo una desregulación y segmentación del mercado de trabajo. Montagut, T. (2004).

Es decir, los problemas generados por la globalización han traído como consecuencia los cambios en el mercado laboral y las prestaciones laborales; dentro de estos cambios están el concepto de salario, las garantías del trabajo dependiente, la estabilidad en el mismo y el reconocimiento de los derechos mínimos que se desdibujan con las formas de contratación comercial y civil.

Desde esta lógica, el Estado tiene una gran responsabilidad en la garantía de acceso al trabajo, de estabilidad laboral y, sobretodo, de velar por el respeto a la dignidad humana y el bienestar del trabajador, propugnando por la aplicación de las normas y principios fundamentales en las relaciones laborales, formales e informales tanto en el ámbito administrativo como en el judicial, con el fin de lograr la legitimación democrática del Estado; tal como en repetidas ocasiones ha señalado la Organización Internacional del Trabajo.

Surge entonces la necesidad de indagar, qué sucede en el diálogo social con las problemáticas que se presentan en la esfera laboral, en vía administrativa y, en mayor medida, en el ámbito 
judicial donde se realizan distintas valoraciones factico - jurídicas, que arrojan como resultado la procedencia o no de reconocimiento de derechos, con los consecuentes pagos económicos o resarcimientos morales.

Es así como, en medio de sociedades pluralistas, en términos morales; diversas y con arraigos, en términos étnico - culturales; y complejas, en términos del funcionamiento de los sistemas, es necesario rediseñar, no sólo procesos e instituciones, sino, sobre todo, re-educar a los ciudadanos para responder, de manera más competente, a los retos que en el Derecho Laboral y de la Seguridad Social se presentan en el Estado actual.

Adela Cortina, (2000) frente a estos cambios de la sociedad, considera en sus escritos que la base de consolidación de una sociedad está en los valores, "no importan por la calidad que proporcionan, sino que una vida humana sin valores no es una vida humana. El "valor" de los valores no puede recogerse en medidas de calidad, sino que valen por sí mismos."

Es de vital importancia consolidar, con eficacia y eficiencia la aplicación normativa en los procesos creados para la garantía de los derechos sustanciales, mediante la promoción de los valores, de los conocimientos y de los criterios de tipo ético y político, en quienes conforman el equipo humano de trabajo, las cuales son la base de toda la estructura estatal y de esta condición se deriva el afianzamiento de la gobernabilidad y la promoción de una democracia participativa, dado el papel determinante del trabajo en la sociedad como derecho humano fundamental, "el trabajo fue $y$ es factor determinante de las grandes transformaciones políticas, sociales y económicas del mundo, teniendo a los esclavos, siervos y obreros como sus principales protagonistas (...)" (Lagos, Luis Arturo, 1999. Pág. 2017).

\section{Cuestionamiento de la flexibilización normativa del Derecho Laboral}

En el normativismo de las relaciones que se generan entre los sujetos de una sociedad cuya dinámica laboral tiene como extremos el que emplea y el que despliega su fuerza física o intelectual en pro del primero, el Estado tiene la obligación suprema de protegerlos, reivindicando así el individualismo y la visión mercantilista del trabajo, donde prime el respeto de derechos y principios universales, bajo criterios de justicia y equidad, que lleven a la transformación del orden social existente.

Es decir, en la época contemporánea se hace referencia a un derecho laboral reivindicatorio de derechos fundamentales nacidos de las relaciones que se generan en el trabajo y que parten de un natural desequilibrio, exigiendo urgentes transformaciones que se adapten a las nuevas realidades que permitan progresivamente y con preeminencia de los valores propios del ser humano, establecer un sistema judicial y administrativo adecuado para evitar que el trabajador sufra algún daño.

Las normas han evolucionado de manera paulatina, flexibilizando cada vez más la otrora rigidez normativa que caracterizaba los códices y leyes nacionales, donde los legisladores fijando estrictas estructuras normativas de obligatorio cumplimiento, para los operadores administrativos y judiciales, no en pocas ocasiones, impedían la verdadera aplicación de la justicia, máxime si se tiene en cuenta que al desconocer los vínculos del Derecho Laboral y de la Seguridad Social con otras ciencias y áreas del conocimiento, el positivismo jurídico generó una importación e imposición de normas del continente europeo, bajo la premisa de que " todo lo extranjero es mejor y de mayor calidad que lo propio", generando una mezcla de normas impositivas en ambientes diferentes con instituciones confusas para el contexto laboral latinoamericano.

Es relevante indicar que los cambios en la Constitución de 1991 en materia de estabilidad del empleo para los trabajadores del sector público y privado, después de una evaluación de dos décadas, han resultado ineficaces, bajo la sombra del derecho a la libertad de empresa y organización de los trabajadores, dando origen legal y reglamentario a las cooperativas de trabajo asociado, a las empresas de servicios temporales y a la desviación jurídica de los contratos sindicales, formas de contratación que son promotoras de la inseguridad jurídica de los trabajadores frente a su verdadero empleador; la dimensión del derecho laboral, va más allá de las situaciones reseñadas en los códigos y leyes, día a día surgen nuevas y extrañas formas laborales que van de la mano con los procesos de cambios tecnológicos y 
el ritmo acelerado de la vida moderna, se habla de la "tercerización", del teletrabajo, del subempleo y del trabajo informal, cuyos parámetros regulatorios tienen en nuestro país desarrollos incipientes, limitados y con vacíos jurídicos.

La responsabilidad del Estado, regulador de políticas administrativas, así como la función de los jueces, adquieren una especial relevancia en la decisión de conflictos generados en esta compleja realidad que no debe valerse únicamente del derecho positivo escrito sino de la aplicación de principios y conceptos universales.

Situaciones y conflictos laborales, requieren no solo la aplicación estricta de una norma en la que un ente mecánico aplica de forma inamovible y taxativa el texto jurídico, sino la permisión para ese funcionario administrativo o judicial de ser creativo en la valoración probatoria, en la posibilidad de inclusión activa de las partes procesales, en la indagación directa de los hechos puestos en su conocimiento y la revisión de las realidades que rodean cada uno de los casos por los cuales son consultados.

Se deberá revisar en un plano práctico si en Colombia se cuenta con la infraestructura administrativa y judicial adecuada para la protección de los derechos del trabajador, es decir, con la capacidad institucional requerida que vaya al compás de los cambios generados en un mundo globalizado, dando una mirada a la actitud de los jueces y administradores cuando las decisiones versan sobre cuestiones subjetivas, también la aptitud para proferir fallos y actos administrativos rápidos y coherentes que definan la problemática planteada, en general se cuestiona si aún nos encontramos ante un "elevado tecnicismo y abstracción del lenguaje jurídico, el excesivo formalismo y la enorme duración de los litigios, convierten al proceso en un laberinto intimidatorio" (Fairen Guillen, La humanización del proceso, 1978, pag.197 citado por J. Bertolini, 2006), en donde la ignorancia o el miedo impiden el acceso a la justicia.

Nos encontramos con un panorama laboral diferente y mundializado que requiere consagraciones constitucionales y normativas basadas en los instrumentos fundamentales de las Naciones Unidas y de los instrumentos elaborados en la Organización Internacional del Trabajo, en consonancia con las realidades que se viven, haciéndose necesario también en esta problemática social atender los derechos bajo la exigencia de considerar a los seres humanos como dotados de dignidad, a quienes se deben garantizar las medidas, que tiene como objeto hacer posible el desarrollo de las capacidades, pero sin extremar su protección, al punto de hacerlos inmovibles en su trabajo y en el peor de los casos, extralimitados en sus derechos en perjuicio del empleador.

Es necesario avanzar en términos de eficacia en las relaciones laborales, mejorar las condiciones de vida de los trabajadores y permitir el desarrollo de las actividades económicas para los empresarios, debe incluirse el componente de legitimidad en las normas que rigen el sistema objeto de estudio así como a los fallos judiciales que día a día se profieren, haciéndolo interdisciplinar para la conformación del sistema, reconociendo la presencia de problemas reales respecto de los modelos teóricos, y no acomodando la realidad a los modelos teóricos impuestos, los cuales no dan respuestas aceptadas a los problemas sociales existentes, máxime si se tiene en cuenta que las tesis fijadas por las Altas Cortes en Colombia, quienes, cada vez más, asumen el papel de "legisladores" motivando decisiones y consecuencialmente "creando" derechos.

\section{La Constitución Política y los cambios normativos, en contraste con la realidad laboral}

Una vez reconocida y desarrollada la teoría del aseguramiento en la prestación de los servicios del Estado Social de Derecho con la influencia del pensamiento político neoliberal, donde la sociedad reconoce en el trabajo la única fuente de ingresos para subsistir, en medio de las dificultades y los peligros, y no como una forma de desarrollo humano y de felicidad, razón por la cual se recibe con esperanza de cambio y reconocimiento positivo de los derechos, la nueva Constitución Política de 1991, en la cual se determinó al Estado Colombiano como un Estado Social de Derecho.

Carta política que en su artículo 1 , así lo considera:

ARTICULO 1. Colombia es un Estado social de derecho, organizado en forma de República 
unitaria, descentralizada, con autonomía de sus entidades territoriales, democrática, participativa y pluralista, fundada en el respeto de la dignidad humana, en el trabajo y la solidaridad de las personas que la integran y en la prevalencia del interés general.

Como fundamento de esta forma de organización del Estado, el artículo 2 consideró dentro de sus fines garantizar la efectividad de los principios, facilitar la participación de todos en las decisiones que los afecten y mantener la vigencia de un orden justo.

ARTICULO 2. Son fines esenciales del Estado: servir a la comunidad, promover la prosperidad general y garantizar la efectividad de los principios, derechos y deberes consagrados en la Constitución; facilitar la participación de todos en las decisiones que los afectan y en la vida económica, política, administrativa y cultural de la Nación; defender la independencia nacional, mantener la integridad territorial y asegurar la convivencia pacífica y la vigencia de un orden justo.

En el marco ideológico, el Estado Social de Derecho consideró incluir en el sistema de derechos fundamentales, no sólo las libertades clásicas, sino también los derechos económicos, sociales y culturales, estando dentro de su ética la protección de los derechos de segunda generación - los derechos sociales, económicos y culturales - lo cual obliga al Estado a ciertos niveles de intervención más allá del laissez faire.

En el Estado Social de Derecho se dan dos justificaciones, primero ética, que genera la obligación de atender la satisfacción de las necesidades fundamentales y el acceso a los bienes básicos, para la garantía de los derechos mínimos, segundo económica, en razón a los fines de la economía, desde Adam Smith como teoría aplicable a nuestros días, por cuanto esta no puede entenderse como una libertad de acumulación individual de la riqueza (Sen. Amartya. 2000).

Es decir, Colombia en teoría, a partir de los cambios e inclusiones sociales establecidas en la Constitución de 1991, ha facilitado la adecuación de lo existente a las nuevas realidades del mundo laboral en armonía con las normas y convenios internacionales, que en mayor medida van a la vanguardia de lo ocurrido en el mundo globalizado.

La Constitución Política de Colombia, como marco de normas reconoce los principios mínimos fundamentales del trabajo y la responsabilidad del Estado en su protección y desarrollo, muestra de ello se lee en la sentencia C-055 de 1999 en la cual se resalta que:

La Constitución del 91 introdujo una gran transformación en la concepción del trabajo al catalogarlo como un derecho $\mathrm{y}$ un deber de toda persona, que goza en sus distintas modalidades de la especial protección del Estado (art. 25 CP.). Uno de los mecanismos instituidos para garantizarlo es indudablemente mediante la expedición de normas generales que, además de regular los aspectos relativos a la prestación individual de servicios, cualquiera que sea el ámbito en que ella se desarrolle, le aseguren al trabajador una vida digna. Con tal fin el constituyente consagró una serie de "principios mínimos fundamentales" (...) constituyen tan sólo un mínimo de derechos para los trabajadores que bien pueden adicionarse con otros que resulten igualmente benéficos o favorables para el trabajador pero jamás desconocerse, pues son mandatos imperativos de obligatorio cumplimiento que impregnan íntegramente el derecho laboral en todos sus órdenes y se constituyen en pauta para su aplicación e interpretación y en garantías que el Estado está obligado a asegurar. (...) resaltando su carácter esencial, el deber de protección y la importancia que ellos adquieren junto con los demás derechos que rigen las relaciones de los trabajadores dentro de una comunidad democrática, participativa y consciente de sus obligaciones.

El reconocimiento de derecho fundamental dentro de la categoría de derecho económico, político y social del derecho de la seguridad social en la Constitución de 1991, trae implícito el derecho a la protección de la integridad de la persona en el medio de trabajo, el cual es materializado en el sistema de riesgos laborales, dentro de las relaciones de trabajo dependientes, derecho que tiene desarrollo en los organismos internacionales, dentro de los cuales encontramos el convenio 87 y el convenio 98 de la OIT, donde se 
solicita de los Estados la obligación de desplegar una actitud de fomento o de acción efectiva de la protección a los trabajadores y su facultad de negociación colectiva, y no solo limitar su actuar a dar garantía al derecho del trabajo (NEVES, 1994: $\mathrm{p}, 16)$.

El Convenio 154 de la OIT fomenta en las naciones el derecho a la negociación colectiva y voluntaria, sin intervención del Estado, entre empleadores y trabajadores, quienes pueden pactar, de común acuerdo, las condiciones de su relación laboral, partiendo de los mínimos exigidos por el Estado, pero superándolos si se quiere en mejores reconocimientos en bienes y servicios, dentro de los que legítimamente se encuentra, el derecho a la protección de la salud y la integridad física. ${ }^{1}$

Estos sistemas consideraron el respeto de los derechos adquiridos, las expectativas legítimas de adquirir los derechos, así como la protección de la vida y la salud en todas sus formas; derechos y principios relacionados con la prohibición a la discriminación, remuneración digna y proporcional, estabilidad laboral, irrenunciabilidad a beneficios mínimos, favorabilidad y condición más beneficiosa, primacía de la realidad sobre las formalidades, garantía a la seguridad social, protección especial de la mujer, a la maternidad y al menor trabajador, garantía a la capacitación laboral y el descanso remunerado, así como al reajuste periódico de las mesadas pensionales.

Al respecto el artículo 53 de la Constitución Nacional, determina:

ARTICULO 53. El Congreso expedirá el estatuto del trabajo. La ley correspondiente tendrá en cuenta por lo menos los siguientes principios mínimos fundamentales:

1 BALVIN TORRES, Edgardo Unilateralismo y Negociación Colectiva, Perú: Pontificia Universidad Católica del Perú 2005, "Ia expresión negociación colectiva comprende todas las negociaciones que tienen lugar entre un empleador, un grupo de empleadores o una organización o varias organizaciones de empleadores, por una parte, y una organización o varias organizaciones de trabajadores, por otra, con el fin de: (a) fijar las condiciones de trabajo y empleo, o (b) regular las relaciones entre empleadores y trabajadores, $o$ (c) regular las relaciones entre empleadores o sus organizaciones y una organización o varias organizaciones de trabajadores, o lograr todos estos fines a la vez".
Igualdad de oportunidades para los trabajadores; remuneración mínima vital y móvil, proporcional a la cantidad y calidad de trabajo; estabilidad en el empleo; irrenunciabilidad a los beneficios mínimos establecidos en normas laborales; facultades para transigir y conciliar sobre derechos inciertos y discutibles; situación más favorable al trabajador en caso de duda en la aplicación e interpretación de las fuentes formales de derecho; primacía de la realidad sobre formalidades establecidas por los sujetos de las relaciones laborales; garantía a la seguridad social, la capacitación, el adiestramiento y el descanso necesario; protección especial a la mujer, a la maternidad $\mathrm{y}$ al trabajador menor de edad.

El Estado garantiza el derecho al pago oportuno y al reajuste periódico de las pensiones legales.

Los convenios internacionales del trabajo debidamente ratificados, hacen parte de la legislación interna.

La ley, los contratos, los acuerdos y convenios de trabajo, no pueden menoscabar la libertad, la dignidad humana ni los derechos de los trabajadores.

El mundo está cambiando a pasos agigantados, los tipos de contratación laboral distan de los que sustentaron las primeras legislaciones, basados en modelos que parten de la tecnología y se escapan del control social y jurídico, surge la necesidad de realizar cambios normativos, se han requerido reformas que miren hacia adelante, que fijen parámetros flexibles y que, sobretodo, no constituyan un retroceso en la dinámica que hoy vivimos, es decir regidos por el principio de progresividad y no regresividad de los derechos sociales, que se encuentran taxativamente reconocidos en las normas internacionales ya descritas y cuyo desarrollo normativo incluye el siguiente contenido.

EL Artículo 2 del Pacto Internacional de Derechos Económicos, Sociales y Culturales (PIDESC), establece que,

cada uno de los Estados Partes en el presente Pacto se compromete a adoptar medidas, tanto por separado como mediante la 
asistencia y la cooperación internacionales, especialmente económicas y técnicas, hasta el máximo de los recursos de que disponga, para lograr progresivamente, por todos los medios apropiados, inclusive en particular la adopción de medidas legislativas, la plena efectividad de los derechos aquí reconocidos.

El artículo 11.1 del PIDESC, establece que, "Los Estados Partes en el presente Pacto reconocen el derecho de toda persona a un nivel de vida adecuado para sí y su familia, incluso alimentación, vestido y vivienda adecuados, y a una mejora continua de las condiciones de existencia."

El Sistema Interamericano de Derechos Humanos consagra de igual forma el principio de progresividad en el artículo 26 de la Convención Americana sobre Derechos Humanos (Pacto de San José de Costa Rica) al considerar que:

Los Estados Partes se comprometen a adoptar providencias, tanto a nivel interno como mediante la cooperación internacional, especialmente económica y técnica, para lograr progresivamente la plena efectividad de los derechos que se derivan de las normas económicas, sociales y sobre educación, ciencia y cultura, contenidas en la Carta de la Organización de los Estados Americanos, reformada por el Protocolo de Buenos Aires, en la medida de los recursos disponibles, por vía legislativa u otros medios apropiados.

El artículo 4ํㅜㄹ del Protocolo de San Salvador, establece que: "No podrá restringirse o menoscabarse ninguno de los derechos reconocidos o vigentes en un Estado en virtud de su legislación interna o de convenciones internacionales, so pretexto de que el Presente Protocolo no los reconoce o los reconoce en menor grado".

Principio que también ha sido recurrentemente resaltado por la Corte Constitucional, que en Sentencia C-177/05 estableció:

25- El anterior análisis permite concluir que las reformas laborales que disminuyen protecciones alcanzadas por los trabajadores son constitucionalmente problemáticas por cuanto pueden afectar el principio de progresividad. Ellas podrían vulnerar la prohibición prima facie de que no existan medidas regresivas en la protección de los derechos sociales. Por ende, la libertad del Legislador al adelantar reformas laborales de este tipo dista de ser plena, pues no sólo (i) no puede desconocer derechos adquiridos sino que además (ii) debe respetar los principios constitucionales del trabajo y (iii) las medidas deben estar justificadas, conforme al principio de proporcionalidad. Esto significa que las autoridades políticas, y en particular el Legislador, deben justificar que esas disminuciones en la protección alcanzada frente a los derechos sociales, como el derecho al trabajo, fueron cuidadosamente estudiadas y justificadas, y representan medidas adecuadas y proporcionadas para alcanzar un propósito constitucional de particular importancia.

A pesar de lo anterior, y ya en la práctica, no puede desconocerse que las normas existentes tienen una perspectiva "monológica", que partió del hecho de un solo concepto - financiero y sostenible - haciendo el legislador uso de la razón, para considerar el DEBER SER del Estado frente a la regulación de los derechos laborales, es decir, no cumpliendo el contenido de las normas laborales y de la seguridad social con las condiciones de una razón dialógica en su creación, al desconocer las teorías de la justicia y de la legitimidad y eficacia de las normas, anteriores a su expedición y vigentes aún, referidas a la existencia de derechos inviolables y de necesario reconocimiento político, desconocen la realidad social y necesidades de los trabajadores y empleadores, las cuales debe ser objeto de una revisión por todos los órganos del Estado, cuando logremos superar las barreras de la política y los intereses personales, para eliminar de nuestro ordenamiento constitucional y legal tan regresivas disposiciones normativas.

Y aunque es verdad que los incesantes cambios en la realidad superan el ritmo del derecho, también lo es que la comunidad internacional, a través de organismos como la Organización Internacional del Trabajo - OIT-, se encuentra cada vez más preocupada porque en las relaciones laborales se prevenga y remedie de fondo, ágil y en verdad de forma reparadora las problemáticas que se presentan, como fundamento para sanar la fragmentación que vive la sociedad mundial, exigiendo del Estado una inversión en recursos humanos, financieros y el establecimiento 
de estructuras estatales que generen en los trabajadores una verdadera confianza en los sistemas. Sin que se trate de realizar constantes reformas normativas o expedir aún más leyes, se busca por lo menos la aplicación práctica de las existentes y su adecuación a las realidades cambiantes.

Ya sea desde la perspectiva de la imposibilidad de continuar bajo un Estado de bienestar, de las dificultades del Estado Social de Derecho, o desde la propuesta de un Estado de justicia, existe un consenso que requiere de un acuerdo: los derechos sociales de los ciudadanos, deben protegerse, garantizarse y promoverse por el Estado, y no permitir que su reconocimiento dependa de los movimientos de la economía y del mercado, en tanto lo que permite una convivencia social, es el reconocimiento de la dignidad humana en las relaciones interpersonales.

El Estado Social de Derecho debe enfrentar los problemas que surgen de las nuevas estructuras sociales, especialmente del entorno familiar, que ha cambiado en su conformación y sostenimiento y el entorno laboral sometido a los cambios de la economía, de la producción, de la tercerización, por la influencia internacional.

Durante las dos últimas décadas ha cambiado la perspectiva de protección, ya no por caridad sino por un desarrollo de los derechos humanos a las personas en condiciones de trabajo o en edad de productividad, regresando estos al concepto de ser sujetos y no objetos de la sociedad ante la notoriedad de su estado de participación social, donde toda teoría del Estado de Derecho tiene como finalidad tutelar efectivamente los derechos y deberes de los seres humanos para librarlos de quienes quieren atropellarlos, incluyendo a los actores dentro del mismo Estado (Rodríguez 0. J. (2009) p. 321).

\section{La autonomía del derecho sustancial respecto del derecho procesal laboral}

Dentro de este contexto cabe revisar la conceptualización del área del derecho surgida de las relaciones de trabajo, encontrando que históricamente ha recibido distintas denominaciones, iniciando en el derecho industrial, pasando por el derecho obrero, corporativo y sindical, hasta llegar al derecho social, derecho al trabajo o derecho laboral que tiene como

(...) finalidad principal la regulación de las relaciones jurídicas entre empresarios y trabajadores y de unos y otros con el Estado, en lo referente al trabajo subordinado y en cuanto atañe a las profesiones y a la forma de prestación de los servicios, y también en lo relativo a las consecuencias jurídicas mediatas de la actividad laboral (...) (Canabellas Guillermo, Tratado de derecho laboral, 1949 citado por Walker Errazuris, 1960, p.17).

El derecho laboral, como rama autónoma, se desprende del derecho civil y surge de la necesidad de enfrentar nuevas relaciones socio económicas que desbordaban el ámbito de las contempladas en los estatutos civilistas, que siempre dominaron el escenario jurídico de nuestra sociedad, y, paralelamente, se desarrolla una legislación procesal para aplicar los nuevos preceptos legales.

No obstante lo anterior, esta autonomía sustantiva y procesal aún arrastra la inequívoca influencia del derecho civil que distorsiona la pretendida autonomía de esta nueva rama del derecho, que no ha logrado estructurar un sistema que se adecue a la nueva realidad procesal que deba partir del hecho real y cierto de que, en estas instancias, las partes no se encuentran en igualdad de condiciones, como si lo están cuando las controversias giran en torno a las relaciones civiles o comerciales.

En otras ramas del derecho, como el caso del derecho penal, el sistema procesal se construye sobre la base de un sistema de garantías para proteger al ciudadano de las posibles arbitrariedades del Estado que, al disponer de todo el aparato coercitivo a su favor, puede incurrir en atropellos que lesionen los principios protegidos sobre los cuales se erige nuestro ordenamiento jurídico: Vida, libertad y propiedad.

En el derecho laboral existe una parte débil, el trabajador, quien es así teóricamente reconocido sustancialmente. Pese a ello el sistema procesal laboral no se fundamenta en ese principio de desigualdad de las partes, desconoce este hecho protuberante que lo convierte en fuente de inequidades por cuanto deja de lado otra consideración básica del derecho laboral como 
rama independiente, como es la protección a la familia, cuyo sustento se obtiene a partir del trabajo remunerado, con todas las ventajas suplementarias como la protección en materia de salud, entre otras.

No tener en cuenta esta nueva realidad en el trámite procesal, constituye un grave error puesto que, so pretexto de la pretendida igualdad, se perpetúa un sistema que no permite restablecer el equilibrio entre las partes.

Lo anterior rompe con las consagraciones de primacía del derecho sustancial sobre el procesal, que han sido estudiadas por la H. Corte Constitucional bajo la línea de "exceso ritual manifiesto" definida en sentencia T-1306 de 2001 (MP Marco Gerardo Monroy Cabra) como:

(...) Aquel que se deriva de un fallo en el cual haya una renuncia consciente de la verdad jurídica objetiva evidente en los hechos, por extremo rigor en la aplicación de las normas procesales convirtiéndose así en una inaplicación de la justicia material, providencia en la que además se señaló que si bien los jueces deben regirse por un marco jurídico preestablecido en el que se solucionen los conflictos de índole material que presentan las partes, no lo es menos que si el derecho procesal se torna en obstáculo para la efectiva realización de un derecho sustancial reconocido expresamente por el juez, mal haría éste en darle prevalencia a las formas haciendo nugatorio un derecho del cual es titular quien acude a la administración de justicia y desnaturalizando a su vez las normas procesales cuya clara finalidad es ser medio para la efectiva realización del derecho material.

Ausencia de protección procesal entre desiguales que se pueden ver en situaciones prácticas con algunas consideraciones de diaria ocurrencia, por ejemplo el reconocimiento de los derechos laborales, por vía judicial o administrativa, en nuestro ordenamiento jurídico, presenta características formales que parten del principio general de derecho expresado en el aforismo da mihi facta, dabo tibi ius (Dame los hechos y te daré el derecho).

Al respecto el profesor Parra Quijano, (2007), sostiene:
(...) De la redacción transcrita se desprende que las partes gozan de igualdad procesal para hacer efectivos sus derechos, pero en principio ni legal ni éticamente, están obligadas a suministrar al juez, toda la información y el acervo probatorio orientado a que se establezca la verdad de lo afirmado, como quiera que solo les interesa exponer los hechos que las beneficien sin considerar si la contraparte se encuentra en desventaja frente a la demostración procesal de esos mismos hechos, de suerte que quien se halle en situación de poder puede, válidamente, omitir toda la información que le resulte contraria a sus intereses con miras a obtener una decisión favorable a sus intereses (...)(p.245).

En el campo laboral uno de los casos más recurrentes se presenta cuando al trabajador se le niega información sobre aspectos vitales de su relación de trabajo que, por su naturaleza, se encuentran bajo la custodia del empleador, tal sería el caso de los registros contables que demuestren el trabajo suplementario desarrollado durante la ejecución de la prestación del servicio. Otro caso similar se presenta si el empleador niega el reconocimiento de lo adeudado por este concepto, con el argumento de no existir su previa autorización escrita, como lo establecen los contratos de trabajo.

Estos dos ejemplos solo pretenden resaltar el hecho cierto, revestido de legalidad, de las muchas maneras como las partes, en este caso los demandados, valiéndose de argucias pueden eludir sus responsabilidades, bajo el amparo de una concepción jurídica del apego a fórmulas rituales del proceso que, lejos de propender por el esclarecimiento de los hechos para develar la verdad de los mismos, se constituye en un entramado de minucias que impiden que aflore la justicia, fin primordial del derecho.

Este tipo de dificultades se origina desde la demanda misma que el legislador ha atiborrado de requisitos que en algunos casos resultan difíciles de cumplir y, en otros, innecesarios y onerosos para el trabajador y cuya incidencia en el resultado final del proceso es nula, ya que no solo se desvía la atención de los fines que se persiguen a través del procedimiento, sino que devienen en la dilación de las reclamaciones, que 
quedarían expuestas a caducidad o prescripción de sus derechos.

La inequidad procesal que afecta al trabajador empieza en la dificultad para tener un pronto acceso a la justicia, considerado como un derecho fundamental, que en la vida diaria, se hace poco menos que imposible por el excesivo formalismo de los requisitos que deben cumplir los trámites administrativos y consecuencialmente la demanda, de acuerdo al Código Procesal del Trabajo, so pena de rechazo o inadmisión, si el juez considera que falta alguno de ellos. Esto podría beneficiar directamente al empleador demandado con lo que, de entrada, se rompe el equilibrio procesal entre las partes, como quiera que se presume que el patrono demandado ha desconocido derechos del trabajador que se pretenden restablecer por vía judicial.

En este replanteamiento también surgen cuestionamientos de renovación de los criterios de valoración probatoria, la pertinencia y funcionalidad de las cargas asignadas en los procesos judiciales, la eficacia de la administración en la atención de quejas, reclamos y en el reconocimiento de derechos, bajo la premisa de protección de derechos inherentes al ser humano, que al ser partes débiles en una relación laboral - contractual ponen en el Estado a través de sus funcionarios y en la rama que administra justicia, mediante los jueces, todas sus esperanzas de reivindicación y reparación.

Así lo estudio la H. Corte Constitucional en sentencia C-372 de 2001 al establecer:

(...) los derechos al trabajo y a la seguridad social no solo exigen la existencia de normas sustantivas que reconozcan los derechos y garantías a favor de los trabajadores, sino que el legislador diseñe e implemente mecanismos para que aquellas puedan hacerse efectivas y reclamables ante la jurisdicción. En efecto, a pesar del margen de configuración del legislador en la determinación de los procedimientos, en el ámbito laboral la Constitución restringe considerablemente el margen de actuación de los órganos políticos, pues el artículo 53 superior incorpora ciertos principios mínimos que obligatoriamente deben ser tenidos en cuenta por el Congreso al regular la materia. En este sentido, el legislativo debe tener en consideración que el procedimiento laboral hace efectivos los derechos consagrados en la referida disposición y, además, cuenta con unas características que lo diferencian de los demás procedimientos establecidos en la legislación colombiana. Por ejemplo, el procedimiento parte del supuesto de que las partes intervinientes en el litigio no se encuentran en un plano de igualdad, toda vez que se presenta una diferencia económica derivada de la relación capital-trabajo. Ello significa que las reglas de cada juicio deben estar encaminadas a garantizar a quienes no cuentan con la capacidad económica suficiente, es decir, a los trabajadores por regla general, la facilidad de gozar de las mismas oportunidades de quien tiene recursos para garantizar su propia defensa. Por ello, una disposición que afecte gravemente la posibilidad de acceder a un determinado recurso judicial en materia laboral, más aún cuando el criterio utilizado es el económico, implica una vulneración de las garantías laborales (...).

Si bien es cierto que con la entrada en vigencia del principio de oralidad, los tiempos procesales han disminuido, no es menos cierto que las consideraciones sobre el fondo de las decisiones en materia laboral, siguen estando sometidas a los rigorismos y formalismos de la exigencia de la "plena prueba" y no en la aplicación de "la carga dinámica de la prueba", como lo pretende en nuevo Código General del Proceso.

Adicional a lo anterior, la oralidad en los procesos laborales ha conllevado a que se deje de evacuar una prueba tan importante como lo es la "inspección judicial", con el afán de cumplir las exigencias procesales y consecuencialmente proferir sentencia con "supuesta" celeridad, lo que a todas luces ha afectado el reconocimiento de los derechos sustanciales del trabajador, al ser falladas sus pretensiones sin el agotamiento de todos los medios de prueba necesarios; sobre todo con las que de oficio puede decretar el juez laboral para alcanzar la verdad real.

Traemos a colación estas acotaciones para señalar una característica de nuestro sistema procesal laboral que, en nuestra opinión, repercute en la lentitud que se presenta en el trámite de algunos procesos. 
Aunado al hecho de la distorsión del principio de inmediación de la prueba, que obliga al juez a practicar personalmente todas las pruebas (artículo 52 C.P.T.) frente a la que abrigamos serias dudas, no solo de su conveniencia sino desde el punto de vista estrictamente jurídico, ya que la consideramos abiertamente inconveniente, dado que, en primer lugar, compromete la imparcialidad y objetividad del juez quien se convierte en testigo obligado de situaciones sobre las cuales se puede formar opiniones que, posteriormente, tiendan a favorecer a una de las partes y, en segundo término, la ley, al no fijarle límites a su función en estas diligencias, lo que le deja en situación de desamparo que puede ocasionarle censura por estimar que no debe intervenir o, de otra parte, si al participar en el desarrollo de la diligencia su proceder es considerado impropio por cualquiera de las partes, lo que podría ser objeto de censura por cualquiera de ellas, con las consiguientes repercusiones procesales.

Otro problema que presenta este principio y que lo continúa desdibujando, se observa en la figura del juez comisionado ya que, en este evento, el juez del conocimiento no solo es ajeno a la práctica de la prueba sino que, ante la imposibilidad de presenciarla in situ, depende para su valoración del criterio del juez comisionado quien, de acuerdo con las directrices jurisprudenciales y según lo dicho por la Corte suprema de Justicia, Corte de Casación Laboral. Sentencia del 4 de octubre de 2000, expediente 14257, M.P. Fernando Velásquez Botero, "recibirá las pruebas por sí mismo y comunicará al comitene su apreciación íntima acerca de ellas, que, en el caso de la prueba testimonial, consistirá en el concepto que le merezcan los deponentes y las circunstancias de mayor o menor credibilidad de sus testimonios".

Principio de inmediación que también en ocasiones se convierte en un factor de dilación procesal, al tener que someter las respectivas diligencias a los trámites burocráticos de la gestión judicial que incluyen el sometimiento a las disponibilidades del juez comisionado, quien se ve obligado a programar la celebración de las diligencias tomando en consideración sus propias obligaciones judiciales.

Todo lo anterior, sin perjuicio del derecho de las partes a hacer uso de las instancias superiores, cuando consideren que el fallo los perjudica y se ven precisadas a ejercer los recursos de ley en procura de revertir decisiones que se reputen contrarias a sus intereses.

Estas situaciones han dado lugar a la búsqueda de soluciones por parte del Estado, empeñado en atender la prestación de los servicios de la rama judicial con la prontitud deseada, lo que se ha intentado sin mucho éxito, tal es el caso de la implementación de despachos judiciales adicionales encargados de descongestionar aquellos que soportan una mayor carga laboral; es decir, de todos es sabido el alto grado de congestión de los despachos judiciales que ha obligado al Estado a recurrir al nombramiento de algunos jueces adicionales con el propósito de desahogar los juzgados de los innumerables procesos represados por exceso de formalismos, entre los que señalamos, a modo de ilustración, obligar a los usuarios a solicitar por escrito desarchive de expedientes, copias de piezas procesales, constancias de asistencia a audiencias, etc, peticiones estas que requieren trámite administrativo interno para ser respondidas y comprometen la disponibilidad de los jueces para cumplir con la obligación de su personal participación en la práctica de las pruebas. La atención de estas particularidades, que bien podrían obviarse sin desmedro del buen trámite de los procesos, militan contra la buena marcha de la justicia.

El fracaso de esta iniciativa, en apariencia idónea, radica en considerar que la congestión judicial obedece al excesivo número de procesos, lo cual es un hecho cierto e innegable, sin tener en cuenta que el verdadero causante de esta situación radica más en los engorrosos trámites procesales, que han convertido nuestros códigos de procedimiento en algo más parecido a manuales de funciones.

A lo anterior hay que añadir los términos para reparto, notificaciones, solicitudes de aplazamiento de audiencias, inconvenientes para ubicar testigos, ausencia de personal de apoyo para la práctica de las pruebas, lo que nos proporciona un panorama bastante desolador de la gestión judicial en nuestro sistema procesal, con las consiguientes dilaciones de los procesos que se refleja en las demoras para ser fallados.

Otro factor que contribuye a las demoras en la solución de los conflictos son, en algunos casos, las innecesarias instancias de conciliación ante 
las autoridades administrativas del trabajo que, por falta de facultades para decidir, se convierten en dependencias burocratizadas, carentes de autoridad, cuya función se limita a escuchar a las partes, sugerir soluciones y dejar constancias.

Estos despachos administrativos deberían convertirse en instancias expeditas para prevenir, más que solucionar conflictos, para lo cual debería dotárselos de un grado de discrecionalidad y de autoridad que redunden en la adopción de medidas correctivas, en casos tales como la revisión de procedimientos convencionales internos, interpretaciones de los reglamentos internos de trabajo, como hacen los juzgados de pequeñas causas.

Igualmente, esta discusión está encaminada a ubicar al papel del juez dentro del principio de libertad procesal que le otorga un margen de discrecionalidad de interpretación para hacer prevalecer el derecho sustantivo, pero no es menos cierto que los jueces y tribunales laborales, en muchas ocasiones, movidos por el justificado interés de que sus fallos prevalezcan en instancias superiores, aplican tímidamente criterios más amplios y acordes con la filosofía y los principios que informan el derecho laboral.

Es por esto que se aboga por una mayor flexibilidad hermenéutica de los jueces al sopesar las pruebas presentadas, dándoles también valor y relevancia a los principios de interpretación de las mismas a la luz de la perspectiva de la preponderancia de la prueba, resaltando como factor para fallar, que los hechos por demostrar sean de tales características que presenten un más alto grado de probabilidad de que sean ciertos $y$, en consecuencia, queden revestidos del consiguiente valor para fundamentar el fallo que en derecho corresponda, sin que ello pueda interpretarse como un intento de inclinar la balanza de la justicia a su favor desconociendo las garantías propias del debido proceso, entre otros principios fundamentales de rango constitucional.

No debe perderse de vista que entre los propósitos fundamentales de las sentencias, está el de corregir los desequilibrios que se producen como consecuencia de decisiones entre los titulares de derechos y los intereses de cada uno de ellos cuando entran en conflicto, sin olvidar que la presunción de debilidad del trabajador se aplica en el procedimiento laboral.
tEl juez se convierte en fuente de conocimiento, $\mathrm{y}$ el funcionario administrativo en su principal discípulo, razón por la cual cobra verdadera importancia resaltar la función social que se tiene, máxime si se trata de los derechos relacionados con el trabajo y la seguridad social, derechos sociales y políticos referidos íntimamente a la dignidad humana y que afectan no solo al individuo que despliega la labor sino también a su núcleo familiar.

\section{Noción de la carga dinámica de la prueba en el proceso laboral}

La Corte Suprema de Justicia - Sala de Casación Civil en sentencia, M.P. Horacio Montoya Gil, auto del 17 de septiembre de 1985, que resolvió una reposición. Gaceta Judicial TOMO CLXXX - No. 2419,1985 , pág. 427 , sostuvo que:

Finalmente, las cargas procesales son aquellas situaciones instituidas por la ley que comportan o demandan una conducta de realización facultativa, normalmente establecida en interés del propio sujeto y cuya omisión trae aparejadas para él consecuencias desfavorables, como la preclusión de una oportunidad o un derecho procesal e inclusive hasta la pérdida del derecho sustancial debatido en el proceso.

Como se ve, las cargas procesales se caracterizan porque el sujeto a quien se las impone la ley conserva la facultad de cumplirlas o no, sin que el Juez o persona alguna pueda compelerlo coercitivamente a ello, todo lo contrario de lo que sucede con las obligaciones; de no, tal omisión le puede acarrear consecuencias desfavorables. Así, por ejemplo probar los supuestos de hecho para no recibir una sentencia adversa. (Negrilla fuera del original).

Para la Corte Constitucional, en sentencia M.P Juan Carlos Henao. Bogotá D.C. 24 de marzo de 2011. Radicación C-203 de 2011, a saber:

(...) las cargas procesales, son un imperativo que también emana de las normas procesales de derecho público y con ocasión del proceso, pero sólo para las partes y algunos terceros. Son del propio interés de quien las soporta, lo que quiere decir que sólo lo favorecen 
a él y no a la otra parte, como ocurre con la obligación o con el deber. Y justamente por esta razón "no existe una sanción coactiva que conmine al individuo a cumplir, sino que se producirá, para el sujeto, como consecuencia de su incumplimiento, una desventaja para el mismo (y no para el otro sujeto). (Negrilla fuera del original).

Es decir que el sujeto procesal que soporta la carga, está en el campo de la libertad para cumplir o no con ella, de modo que si no lo hace no está constreñido para que se allane a cumplirla, por lo cual el no asumirla no dará lugar propiamente una sanción sino a las consecuencias jurídicas propias de su inactividad, que pueden repercutir también desfavorablemente sobre los derechos sustanciales que en el proceso se ventilan.

Ahora que, con todo y haberse dicho que el incumplimiento de la carga procesal no es en sentido estricto sancionable, es cierto que la omisión de su realización puede traer consecuencias desfavorables para quien la soporta. Ellas pueden consistir en la preclusión de una oportunidad o de un derecho procesal, hasta la pérdida del derecho material, como lo ha referido la Corte Constitucional, en sentencia M.P Juan Carlos Henao. Bogotá D.C. 24 de marzo de 2011. Radicación C-203 de 2011, en la que estableció:

(...) dado que el sometimiento a las normas procedimentales o adjetivas, como formas propias del respectivo juicio, no es optativo para quienes acuden al mismo con el objeto de resolver sus conflictos jurídicos, en tanto que de esa subordinación depende la validez de los actos que de ellas resulten y la efectividad de los derechos sustanciales.

Si bien es cierto que con la entrada en vigencia del principio de oralidad, los tiempos procesales han disminuido, no es menos cierto que las consideraciones sobre el fondo de las decisiones, sigue sometido a las características y formalismos más acordes con los preceptos del derecho penal que, como se sabe, exige la plena prueba, es decir, que sea completa y sin sombra de duda para decidir de fondo la controversia.

Al respecto, el autor DEVIS ECHANDIA, 2007 (p. 197 - 198) sostiene que la carga de la prueba es:
(... ) una noción procesal, que contiene la regla de juicio por medio de la cual se le indica al juez cómo debe fallar, cuando no encuentra en el proceso pruebas que le den certeza sobre los hechos que deben fundamentar su decisión, e indirectamente establecer a cuál de las partes le interesa la prueba de tales hechos, para evitarse las consecuencias desfavorables a ella o favorables a la otra parte (...).

(...) la carga de la prueba no significa que la parte sobre quien recae deba ser necesariamente quien presente o solicite la prueba del hecho que fundamenta su pretensión o excepción sino que señala apenas a quién interesa la demostración de ese hecho en el proceso. Se exige que aparezca la prueba, más no importa quién la aduzca. De ahí que consideramos incorrecto decir que la carga de la prueba determina quién debe probar cada hecho, pues únicamente señala quién tiene interés jurídico en que resulte probado, porque se perjudica o sufre la consecuencia desfavorable de su falta de prueba; sólo cuando no aparece ésta, corresponde determinar la parte que debía evitar su omisión. Es decir: indica a quién corresponde evitar que falte la prueba de cierto hecho, si pretende obtener una decisión favorable basada en él, pero si el juez o la contraparte la suministran, queda cumplido el interés de quien era sujeto de tal carga y satisfecha ésta. Si es un hecho exento de prueba, no existe carga de probarlo (...).

El Autor PARRA QUIJANO, 2004 (p.242), manifiesta que

(...) no es la carga una obligación ni un deber, por no existir sujeto o entidad legitimada para exigir su cumplimiento. Tiene necesidad que aparezca probado el hecho la parte que soporta la carga, pero su prueba puede lograrse por la actividad oficiosa del juez o de la contraparte.

Y en la actualidad, resulta necesario hacer alusión a un concepto moderno denominado "La carga dinámica de la prueba", tema al cual el autor TAMAYO JARAMILLO . 1993 (p.91) se ha referido aduciendo que 
No se trata de que a priori y como principio general inmutable, se invierta la carga probatoria que incumbe a una de las partes. De lo que se trata es de obligar a todos los contendientes a aportar todas las pruebas que estén a su alcance para lograr el conocimiento de la verdad real.

Sobre la carga dinámica de la prueba la $\mathrm{H}$. Corte Suprema de Justicia - Sala de Casación Laboral en sentencia de 3 de Mayo de 2006 señaló lo siguiente:

Recientemente al explicar cómo opera la carga de la prueba de la culpa de un empleador a quien se le reprocha su negligencia y memorar el criterio de antaño expuesto sobre este asunto por el Tribunal Supremo de Trabajo, precisó esta sala de la Corte en sentencia del 10 de Marzo de 2005, radicación 23656 "ciertamente una vez se demuestra que la causa eficiente del infortunio fue la falta de revisión por parte de la persona encargada de prevenir cualquier accidente, como medida de seguridad adoptada al efecto por la empresa, la carga dinámica de la prueba se traslada a ésta, dada su calidad de obligada que no cumple satisfactoriamente con la prestación debida de conformidad con el artículo 216 del CST en concordancia con las normas que regulan la responsabilidad contractual (...).

Por su parte la Corte Constitucional en sentencia T-423 de 2011 ratificó:

(... ) para solucionar una controversia, lo primero que debe hacer el juez es determinar con claridad cuál es el asunto en conflicto, es decir, cuáles son los hechos que le dieron origen. De allí que, por regla general, a cada parte le corresponda probar los hechos que aducen como fundamento de sus pretensiones.

Estas reglas se conocen "como Onus prodandi, incumbit actori y Reus, in excipiendo, fit actor, esto es, respectivamente, que al demandante le incumbe el deber de probar los hechos en que funda su acción y al demandado, cuando excepciona o se defiende, le corresponde, a su turno, probar los hechos en que se sustenta su defensa".

Sin embargo, la regla anterior en virtud de la cual quien alega debe probar los hechos en los que fundamenta su pretensión, debe ser aplicada con menor rigor en sede de tutela y "debe ser interpretada en el sentido de que la parte afectada pruebe lo que alega en la medida en que ello sea posible, pues ha de tener en consideración la especial situación de debilidad o subordinación en que se encuentre el accionante para acceder a la prueba, lo que a su vez enfatiza la obligación del juez de tutela en el marco probatorio de realizar una actividad oficiosa para el esclarecimiento de los hechos base de la acción.

De manera que en el trámite de la acción de tutela, se aplica el principio de la carga dinámica de la prueba según el cual y de acuerdo nuevamente con la H. Corte Constitucional Sentencia T-423 de 2011:

(...) corresponde probar un hecho determinado, a quien se encuentre en mejores condiciones para hacerlo". En efecto, "la carga probatoria en el trámite de la acción de tutela, es más exigente para los demandados que para los accionantes, en virtud de la naturaleza especial de esta acción y del principio de quien puede probar tienen la carga de hacerlo. Este principio, alivia la carga de los accionantes, quienes usualmente son personas que carecen de los medios para probar todos y cada uno de los hechos por ellos relatados".

En la actualidad el nuevo Código General del Proceso ha definido el concepto en el Art. 167 que a su tenor contempla:

CARGA DE LA PRUEBA. Incumbe a las partes probar el supuesto de hecho de las normas que consagran el efecto jurídico que ellas persiguen.

No obstante, según las particularidades del caso, el juez podrá, de oficio o a petición de parte, distribuir, la carga al decretar las pruebas, durante su práctica o en cualquier momento del proceso antes de fallar, exigiendo probar determinado hecho a la parte que se encuentre en una situación más favorable para aportar las evidencias o esclarecer los hechos controvertidos. La parte se considerará en mejor posición para probar en virtud de su cercanía con el material probatorio, por tener en su poder el objeto de prueba, por circunstancias técnicas especiales, por haber 
intervenido directamente en los hechos que dieron lugar al litigio, o por estado de indefensión o de incapacidad en la cual se encuentre la contraparte, entre otras circunstancias similares.

Cuando el juez adopte esta decisión, que será susceptible de recurso, otorgará a la parte correspondiente el término necesario para aportar o solicitar la respectiva prueba, la cual se someterá a las reglas de contradicción previstas en este código.

Los hechos notorios y las afirmaciones o negaciones indefinidas no requieren prueba...". (Negrilla y subrayado fuera de texto).

Así las cosas, es evidente que la carga de la prueba en materia laboral debe estar en cabeza de quien tenga una mejor posición para demostrar los hechos alegados objeto de demanda o de contestación de demanda, con el fin de llegar a la verdad real, independiente que se trate de trabajador o empleador.

\section{CONCLUSIONES}

El desarrollo del Derecho Laboral y de la Seguridad Social colombiano presenta atrasos y problemáticas profundas, resultado de la copia e importación acrítica de normas e instituciones, gigantismo normativo, esnobismo, contradicciones internas, derogaciones implícitas en las decisiones administrativas y judiciales, inaplicabilidad y conflictos de normas y de competencias y administración de justicia reducida, que afecta el reconocimiento de los derechos sustanciales de los trabajadores.

Este panorama jurídico laboral es derivado de la herencia kantiana en la búsqueda de la "pureza" en el Derecho como "ciencia", en la que se propugna por la neutralidad de las autoridades administrativas y judiciales al momento de impartir justicia, que lleva a concluir que en principio no se necesita realizar reformas legislativas, sino cambios estructurales desde los funcionarios administrativos (inspectores de trabajo, entes de control, operadores administrativos) hasta la base de aplicación y de solución de reclamaciones con la adecuada utilización de los mecanismos de solución de conflictos, siendo la última instancia el escenario judicial, en el que también se requieren cambios de mentalidad, seres creativos y arriesgados que visualicen que más allá de las normas existe un derecho con rostro humano que proteger.

Se trata de desarrollar los derechos y principios mínimos existentes, dignificando al ser humano que trabaja y que constituyen la base social de una economía globalizada, siendo en primer medida y de forma restrictiva el funcionario administrativo y posteriormente y de manera amplia y particular los jueces, los encargados de encontrar el equilibrio entre los principios protectores y las relaciones laborales nacidas ya sea de un contrato escrito o verbal.

Por lo anterior, se requiere de la aplicación del derecho de manera evolucionada y adaptable a la realidad nacional, donde ya no el legislador sino la administración y los jueces tienen la responsabilidad de la protección efectiva de los derechos presuntamente vulnerados al trabajador, partiendo de la base que se trata de un derecho humano con todas sus complejidades, pero que exige la eficiencia de la justicia para el amparo de sus pretensiones.

Resulta necesario fijar estructuras solidas que cuenten con una adecuada preparación de los operadores administrativos y judiciales en la aplicación de los principios que protegen el derecho al trabajo y la seguridad social, brindándoles herramientas e instrumentos que les permitan realmente emitir juicios valorativos menos anacrónicos, logrando de esta manera acercar el Derecho a la realidad, con una aplicación eficiente de las normas y la satisfacción efectiva de los derechos.

En cuanto a la función judicial es imperativo que el juez circunscriba sus decisiones a las pruebas aportadas por las partes, en aplicación de la figura de la carga dinámica de la prueba regulada recientemente por el Código General del Proceso, lo que implica que más allá del formalismo procesal puedan reconocerse realmente los derechos y pretensiones a quien corresponde. 


\section{BIBLIOGRAFÍA}

\section{Doctrina}

- Cortina Orts, Adela. (2000). El vigor de los valores morales para la convivencia Artículo en La educación y los valores. Madrid: Fundación Argentaria/Biblioteca Nueva.

- Devis Echandia, Hernando. (2007). Compendio de la Prueba Judicial. Argentina: Rubinzal-Culzoni Editores.

- Galgano, Francesco. (2005). La Globalización en el espejo del Derecho. Argentina: Editorial Rubinzal - Culzoni Editores

- J. Bertolini. (2006). Proceso, democracia y humanización. Recuperado de www. monografías.com

- Keynes, J. (2007). Las consecuencias económicas de la paz. Barcelona: Crítica.

- Lagos, Luis Arturo. (1999). "Deslaborización de la relación de trabajo". En: Silva Romero Marcel. El derecho Laboral que hereda el milenio (pp. 217-238). Bogotá: Unibiblos.

- Mejía, 0. (2005). Teoría política, democracia radical y filosofía del derecho: legitimidad, validez y eficacia en el pensamiento contemporáneo. Bogotá: Temis.

- Montagut, T. (2004). Política Social. Madrid: Ed. Ariel.

- Neves Mojica, Javier. (1994). Negociación colectiva, No. 47- Lima.

- Parra Quijano, Jairo. (2007). Manual de Derecho Probatorio. Bogotá: Librería Ediciones del Profesional.

- Rodríguez Ortega, J. (2009). La legitimidad en el Estado Social de Derecho., Bogotá: Grupo Editorial Leyer.

- Sen, A. (2000). Desarrollo y libertad. Barcelona: Planeta.
- Tamayo Jaramillo, Javier. (1993). Responsabilidad civil médica en los servicios de salud. Medellín: Biblioteca Jurídica Dike

- Viola, F. y Zaccaria, G. (1999). Derecho e interpretación. Elementos para una teoría hermenéutica del derecho. Instituto de Derechos humanos Bartolomé de las Casas. Madrid: Universidad Carlos III.

- Walker Errazuris, Francisco (1960). Introducción al estudio del derecho al trabajo. Santiago de Chile. Editorial Jurídica de Chile.

- Jurisprudencia

- Colombia. Corte Constitucional. Sentencia C-055 de 1999.

- Colombia. Corte Suprema de Justicia, Sala de Casación Laboral. Sentencia del 4 de octubre de 2000, expediente 14257, M.P. Fernando Velásquez Botero

- Colombia. Corte Constitucional. M.P Juan Carlos Henao. Bogotá D.C. 24 de marzo de 2011. Radicación C-203 de 2011.

- Colombia. Corte Suprema de Justicia - Sala de Casación Laboral en sentencia de 3 de Mayo de 2006

- Colombia. Corte Suprema de Justicia - Sala de Casación Laboral. M.P Francisco Javier Ricaurte. Bogotá D.C. 3 de mayo de 2006. Radicación No. 26126

- Colombia. Corte Constitucional. M.P Juan Carlos Henao. Bogotá D.C. 17 de mayo de 2011. Radicación T - 423 de 2011

- Colombia. Corte Constitucional. Sentencia C-177/05

- Colombia. Corte Constitucional. Sentencia T-1306 de 2001

- Colombia. Corte Suprema de Justicia - Sala de Casación Civil. Sentencia, M.P. Horacio Montoya Gil, auto del 17 de septiembre de 1985, que resolvió una reposición. Gaceta Judicial TOMO CLXXX - No. 2419, 1985 


\section{Legislación}

- Colombia. Constitución Política Colombiana. 1991. Asamblea Nacional Constituyente.

- Colombia. Ley 100/1993 de 23 de diciembre. Congreso de la República de Colombia.

- Colombia. Ley 1574/2010 de 2 de agosto.
Congreso de la República de Colombia.

- Convenio 154 de la OIT

- Pacto Internacional de Derechos Económicos, Sociales y Culturales (PIDESC)

- Convención Americana sobre Derechos Humanos (Pacto de San José de Costa Rica)

- Protocolo de San Salvador 
